\title{
Chroma-Memo-Flow Technique for Rapid Sequential Analysis of Regional Cerebral Blood Flow (rCBF) Responses
}

\author{
JØRN OVERGAARD
}

SUMMARY: This is the first report of a method of sequential regional cerebral blood flow ( $\mathrm{rCBF}$ ) analysis, called Croma-Memo-Flow. This technique is a computerized modification of the initial slope method of regional cerebral blood flow ( $\mathrm{rCB} F$ init.), allowing temporal resolution of the flow pattern by calculation of the slopes of sequential segments of the initial l-2 minutes of the Xenon-133 washout curve. The same theoretical analysis applies to this method as to the rCBF init. method. Each flow calculation is based on the slope of a discrete 16 second segment of the initial washout; and each second the segment is advanced by one second. $A$ new flow calculation is made each second and is displayed as a color coded map on a TV screen. Each map is label-

RÉSUMÉ: Il s'agit de la première publication concernant une méthode d'analyse du flot cérébral régional (rCBF) de façon séquentielle, et qui a nom: Croma-Memo-Flow. Cette technique est une modification sur ordinateur de la méthode de la pente initiale pour mesurer le flot cérébral régional ( $\mathrm{rCBF}$ init.). Elle permet une résolution selon le temps des pentes des segments séquentiels des 1-2 minutes initiales sur la courbe au Xenon-133. La même analyse théorique que pour la méthode rCBF init. s'applique ici. Chaque calcul du flot est basé sur la pente d'un petit segment de 16 secondes de la phase initiale. Un nouveau calcul de flot est fait à chaque seconde et est visualisé sur l'écran de télévision selon une carte en couleur. Chaque carte est marquée du

From the Neurosurgical Department, University Hospital, DK-5000 Odense C, Denmark.

Reprint requests to: Dr. Jørn Overgaard, Chief Neurosurgeon, Department of Neurosurgery, Odense University Hospital, DK-5000 Odense C, Denmark. led, indicating the time in seconds following Xenon injection, and sequential $r C B F$ changes during the clearance period can be immediately visualized. This allows for almost instantaneous analysis and display of rapid or transient $r C B F$ responses to activation and deactivation of the cerebral cortices.

The data is stored in a 35 channel memory for deliberate replay, photography, and analysis.

Functional tests may be applied during the initial washout period and both the magnitude and chronological relationships of the evoked regional cerebrovascular responses observed. A clinical study is presented to illustrate the possibilities of applying the technique to assess cortical reactivity.

temps écoulé (en secondes) depuis l'injection de Xenon et ainsi tout changement du rCBF séquentiel durant le période de "clearance" peut être immédiatement observé. Ceci permet l'analyse et la visualisation presqu'instantannée de toute modification consécutive à l'activation ou la déactivation des cortex cérébraux.

Les données sont également enregistrées sur mémoire à 35 canaux pour reprise, photographie et analyse.

Ainsi des tests fonctionnels peuvent être accomplis durant la période initiale et on peut observer l'amplitude et les relations chronologiques de la réponse cérébrovasculaire régionale à la stimulation. L'auteur illustre cette capacité d'évaluer la réactivité corticale par un exemple clinique détaillé.

\section{INTRODUCTION}

Recent studies have demonstrated that mentation and sensory-motor activity cause a measurable change of cerebral blood flow in conscious man (Ingvar and Risberg, 1967; Ingvar and Gustafson, 1970; Ingvar and Franzen, 1974; Olesen, 1971; Risberg and Ingvar, 1973). Other investigations have shown a good correlation between flow increases and oxygen uptake and thereby supported the hypothesis that flow increments under these conditions reflect the augmented metabolic demands of the involved cerebral tissue (Raichle et al., 1976).

The pertinent analysis of flow events was made possible by the introduction of the initial slope method (rCBF init.), which reduced the time scale for the measurement of rCBF from 10 minutes to $60 \mathrm{sec}$ onds (Lassen Ingvar, 1972; Olesen et al., 1971; Sveinsdottir et al., 1977). The development of multidetector analysis of the clearance of Xenon-133 has uncovered a second dimension of the dynamics of cerebral blood flow, the "spatial" resolution of circulatory responses to changes of brain function. A detailed mapping of the functional anatomy of the convexities of the cerebral hemisphere has resulted from these studies (Ingvar, 1976; Larsen et al., 1976; Roland and Larsen, 1976).

This communication deals with a third aspect, the temporal resolution or the time scale of cerebral circulatory responses. Attempts will be made to define the problem and, referring to the rCBF init. method, a technical solution is presented. The clinical application is illustrated by a 
patient study and advantages and limitations are discussed.

\section{DIMENSIONS OF THE PROBLEM}

Insight into the chronology of regional circulatory events occurring with brain activation requires time analysis of 1) the interval between stimulation and flow response and 2) the flow changes.

Considering the time scale of psycho-physical activity in relation to measurement of cerebral blood flow, (Albert and Bear, 1974; Dykes et al., 1977; Efron, 1963; Glickstein, 1972; Mosfeldt Laursen, 1967; Severinghaus, 1975) the object has been to $r$ :sign and construct equipment witn characteristics that will make it possible to a) follow cerebral blood flow from moment to moment, b) identify the time relations between circulatory changes in different regions of the hemisphere convexities and c) determine the time relation between start and stop of performance and flow increments and decrements.

\section{DESCRIPTION OF THE EQUIPMENT *}

The gamma-detecting system is a conventional multi-detector apparatus with 35 scintillation detectors mounted in fixed positions in a cassette. The pulses from the photomultipliers are amplified and discriminated in 35 separate, lower level discriminators, adjusted for the $82 \mathrm{keV}$ line in Xenon-133. The output pulses from the discriminators are accumulated during each one second period and stored in a 35 channel memory with a capacity of $2^{13}(8192)$ counts per channel, i.e. equal to a total count rate of $8192 \times 35=286,720$ counts per second.

A microcomputer system has been developed for the calculation of the flow values in accordance with the formula for the initial slope method: $C B F$ init.= lambda grey $x$ in (10) $\times \mathrm{D} \times 100(\mathrm{~m} / / 100 \mathrm{~g} / \mathrm{min})$. Lambda is the tissue to blood partition coefficient for xenon.

$D$ (slope in decades per minute) is the numerical value of the slope of the clearance curve in base 10 logarithmic system, (i.e. the logarithm ot the count rate) and is calculated as a linear-regression of the clearance curve (Lassen \& Ingvar, 1972; Olesen et al., 1971).

The flow calculation is performed upon the discriminator output pulses during 16 successive seconds. Each flow calculation is based upon the slope of a sixteen second interval of

\footnotetext{
* This description and the construction of the Chroma-Memo-Flow equipment was made by Carlo Andreassen and Lars Magnussen of the Memotek aps, Vestergade 30, DK 8900 Randers, Denmark, telephone (06) 43 8104.
}

the xenon-133 washout curve. A new flow value is calculated every second and the measuring time of 16 seconds is kept constant by including the output pulses of the next second in the computation and excluding the counts of the first second of the previous 16 second period (i.e. $=$ the first or oldest second). The calculated flow values are converted into color signals (Croma-Flow) and displayed on a color TV-monitor in 35 fields, representing 35 regions of the brain, identified by the position of the detectors.

Calculation of the flow values, their conversion to color signals and display on the TVscreen is completed in less than one second and pictures are consequently generated at a rate of one per second. They are identified by a digit (T 000,001. . . 600), indicating time in seconds following Xenon injection $(=$ start of program see Fig. 1 and 2).

Following each Xenon injection into the internal carotid artery the circulatory events can be followed directly during the clearance period, but the data are also stored (MemoFlow) on a tape for late replay and an automatic camera is connected to the TV-display for color photography. The color scale represents flow intervals, as illustrated in Fig. 1 and 2. The high range can be activated on replay when regional flow values are over 111 $\mathrm{ml} / 100 \mathrm{~g} / \mathrm{min}$. When a slope can not be calculated the color display will indicate this by turning the region white on the screen. A flow value over $255 \mathrm{ml} / 100 \mathrm{~g} / \mathrm{min}$. will be displayed as white. This will also occur when the counting rate for one detector exceeds 8192 counts/second. If the patient should move his head a number of regions will turn white, but an equal number will jump to higher color values at the same second and this event is therefore immediately discovered by the observer.

\section{Theoretical considerations}

The theoretical basis of the Croma-Memo-Flow technique is similar to that of the $C B F$ init. method of calculating cerebral blood flow. In normal brain the xenon- 133 clearance curve can be dissected into two exponential components, representing flow in grey and white matter. When the two calculated flows differ widely, as grey and white normally do, the faster component dominates the early part of the washout. Therefore the initial 1-2 minutes of the clearance curve is for practical purposes monoexponential and is considered to estimate grey matter flow. (Olesen et al., 1971). If one then uses a constant value for lambda (the tissue to blood xenon partition coefficient), flow values calculated from any portion of the initial mono-exponential clearance curve will be identical in the steady state.
The clearance curve is not always, however, only mono- or biexponential. Detectors placed directly over large vessels will register "shunt spikes" and in some pathologic states small tissue compartments with very high flow are seen as "tissue peaks". Because they represent rapid transit of the isotope these "peaks" are evident only at the initial portion of the clearance curve. In a multiexponential curve the "faster" tissues will dominate the early part of the curve and the slope will decrease progressively with time.

A sudden increase in the clearance slope in the time period between 15 seconds and 2 minutes may be factitious or may indicate a real increase in the rate of isotope washout from grey matter. Factitious changes are seen with sudden movement of the patients' head, changing the tissue to detector geometry, and would be evident in all detectors. Increased rate of clearance in only a few detectors indicates increased rate of isotope washout, i.e. increased perfusion.

The correct choice of a value for lambda involves some uncertainty. Theoretically, if different tissues with different washout rates contribute to the clearance curve, the correct value for lambda may change with time. Due to the uncertainty in predicting this, and because grey matter dominates the clearance within the portion of interest, the lambda for grey $(0.87)$ is used throughout.

The limitation of the Croma-Flow technique is the accuracy with which a least-squares slope can be calculated for a short segment of the clearance curve. This requires count rates high enough to reduce statistical randomness and background noise to acceptable levels. This is accomplished with the intra-arterial injection of 1-2 millicuries of xenon and the capacity to handle these count rates $\left(2^{13}\right.$ counts per channel per second) is in the memory.

\section{A PATIENT STUDY}

A 40-year-old woman had, under local analgesia, a cerebral blood flow investigation with xenon-133 in- 


\section{$\mathrm{CBF}$ init $/ \mathrm{ml} / 100 \mathrm{~g} / \mathrm{min}$}

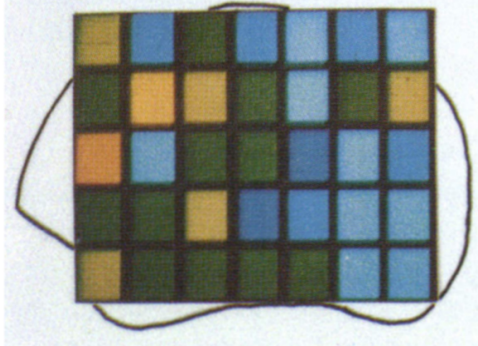

$$
\begin{array}{r}
<20 \\
31-40 \\
51-60 \\
71-80 \\
91-110
\end{array}
$$

\section{R3 $928-77 \quad 7059$ M1S}

Figure I - The Croma-Flow picture of second 59 (T 059). R 3 refers to Xenon injection number 3. 28-77 denotes study number of the year. $\mathrm{M} 1$ denotes that flow was calculated upon the 16 second clearance. L denotes the color code, range Low.

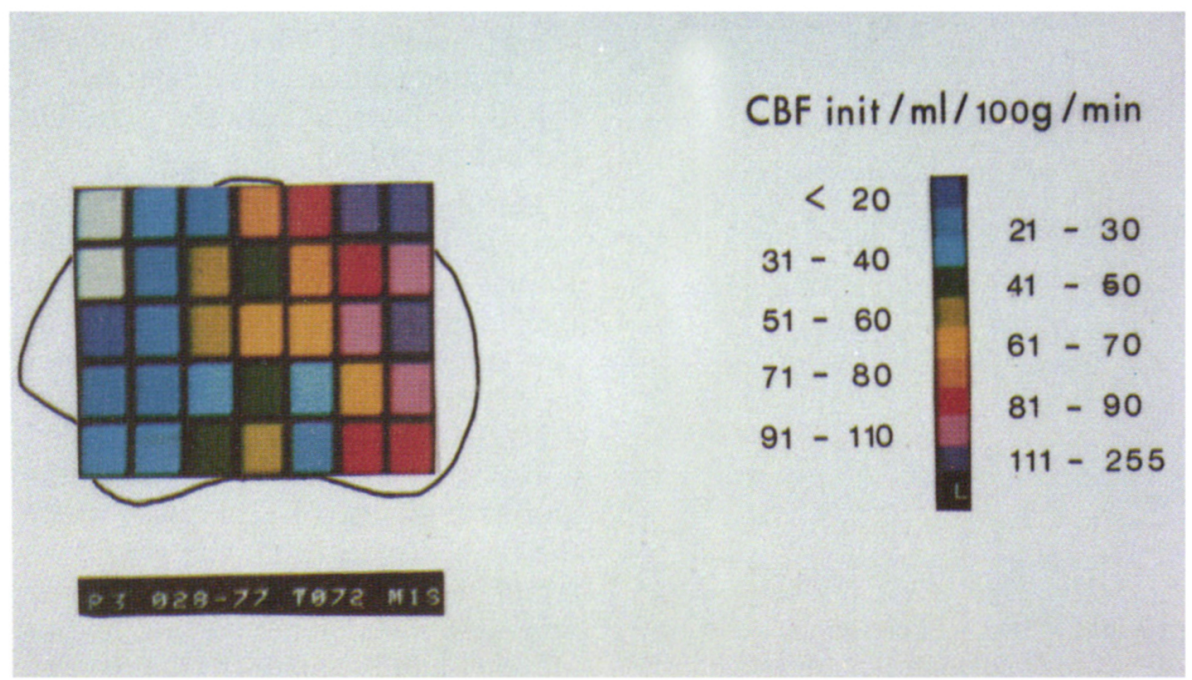

Figure 2 - The Croma-Flow picture of the second nr. 72 (T 072 ). i.e. 13 second after application of a sudden hand clasp. The marked increases of regional flow in the parieto-occipital areas occurred at the expense of flow in frontal regions. This figure should be compared with figure 1. The black lattice of the color pictures are made by the pattern generator. Regional location is corrected in Figure 3-7.

jected through a catheter placed in the left internal carotid artery. The patient was undergoing preoperative examination for a left middle cerebral artery aneurysm, two weeks after subarachnoid hemorrhage. Her previous condition of stupor and aphasia had cleared completely following continuous drainage of ventricular fluid for 10 days and at the time of study she was awake and without neurological deficits, except for a severe bilateral hearing loss caused by ancient middle ear infection.

She had been informed about the procedure the day before the investigation. The studies were done when a carotid angiogram was of diagnostic necessity. The patient was resting comfortably on a cushioned operating table with her eyes closed and covered with a cloth. The cassette, with 35 detectors, was placed on the left side of her head. It covered most of the cortical regions of the left hemisphere.

A supporting pillow was placed on the right side.

The position of the detectors was determined by superposition of lead marked $x$-rays and angiograms made after completion of the flow investigation.

The standard hemodynamic measurements in this study are: Monitoring of mean arterial blood pressure (MABP), mean intraventricular pressure (MIVP), and blood gas analysis of internal jugular venous and internal carotid arterial blood. Calculations are of mean hemispheric $\mathrm{CBF}$ init. (mhCBF init.), regional $\mathrm{CBF}$ init. ( $\mathrm{rCBF}$ init.), mean hemispheric $\mathrm{CBF} 10$ (mhCBF10), regional CBF10 (rCBF10) and CMROz.

\section{RESULTS}

Under the above mentioned resting conditions the following results were recorded: $\mathrm{mhCBF}$ init.: 45 $\mathrm{ml} / 100 \mathrm{~g} / \mathrm{min}$, $\quad \mathrm{mhCBF} 10: 43$ $\mathrm{ml} / 100 \mathrm{~g} / \mathrm{min}$., $\mathrm{PaCO}_{2}: 36$ torr, MABP: $120 \mathrm{~mm} \mathrm{Hg}$, MIVP: $4 \mathrm{~mm} \mathrm{Hg}$, CMRO2: $1,78 \mathrm{ml} / 100 \mathrm{~g} / \mathrm{min}$. A similar set of results were obtained at a second test or control run: $\mathrm{mhCBF}$ init.: $44 \mathrm{ml} / 100 \mathrm{~g} / \mathrm{min}$., $\mathrm{mhCBF} 10: 42$ $\mathrm{ml} / 100 \mathrm{~g} / \mathrm{min} ., \mathrm{PaCO}_{2}: 37$ torr, MABP: $122 \mathrm{~mm} \mathrm{Hg}$, MIVP: $5 \mathrm{~mm}$ $\mathrm{Hg}, \mathrm{CMRO}_{2}: 1,85 \mathrm{ml} / 100 \mathrm{~g} / \mathrm{min}$.

During this second run the author suddenly, without warning, clasped the patient's right hand between both of his hands. This happened at second nr. 59 and lasted until second $\mathrm{nr}$. 75.

A. Chronology of Regional CBF: Changes during a Sudden and Unexpected Hand Clasp.

The regional flow changes following the hand clasp at second $\mathrm{nr} .59$ are illustrated by the Croma-Flow pictures of second $\mathrm{nr}$. 59 (Fig. 1) and second nr. 72 (Fig. 2). The flow maps indicate a great increase of regional flow in the parieto-occipital areas and a lowering of flow in the frontal areas. The temporal lobe area had a nearly unchanged Croma pattern.

The circulatory response to the hand clasp did not occur at the same time in the different areas. The time 
Regional flow changes induced by unexpected hand clasp

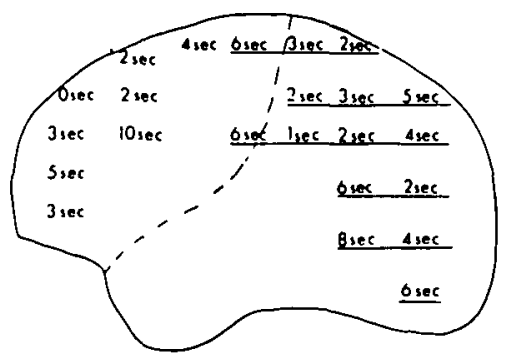

laiency from signal to llow changes stort

Figure 3 - Lateral view of left hemisphere. The time relation indicates the latency from the hand clasp until regional flow change started. Time in seconds. In regions where flow increased the figure is underlined. Regions where no flow change occurred are not indicated a by a number.

Regional flow thanges induced by unexpected hand clasp

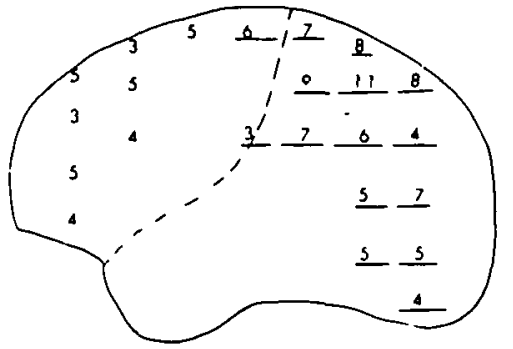

Time intervol in secands from begin 10 end of flow changes -octivation periods

Figure 4 - Lateral view of left hemisphere. Period of flow change: From end of latency until culmination of flow change (=activation period in seconds). Figures underlined denote regions where flow increased.

Regronal Hlow changes induced by unexpecied hand closp

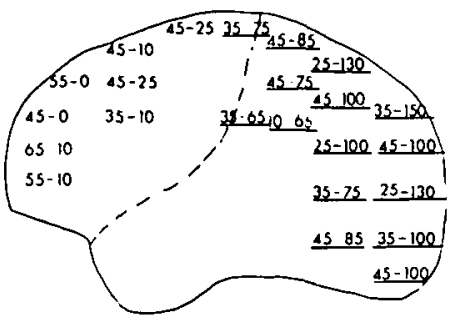

Croma llow before and ot the sutmination of sirculatory activation

Figure 5 - Flow changes following a sudden unexpected hand clasp. The left of each pair of figures denotes the Croma-Flow value at the end of the latency period, that to the right the Croma-Flow of the region at the end of the activation period.
Regional flow changes induced by une xpected hand closp

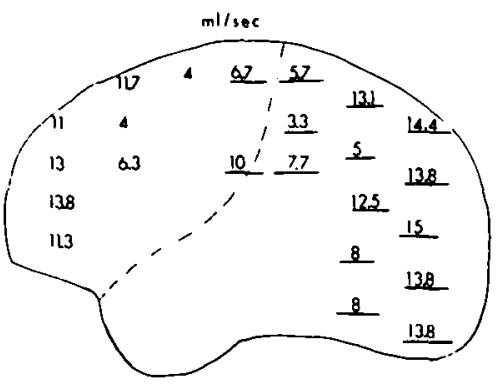

Flow changes pr. second pr. region

Figure 6 - Flow changes following a sudden unexpected hand clasp. The figure at each region denotes flow change per second per region. The figure is obtained by dividing the difference between each pair of numbers shown in Figure 5 with the regional activation period, measured in seconds, as indicated in Figure 4.

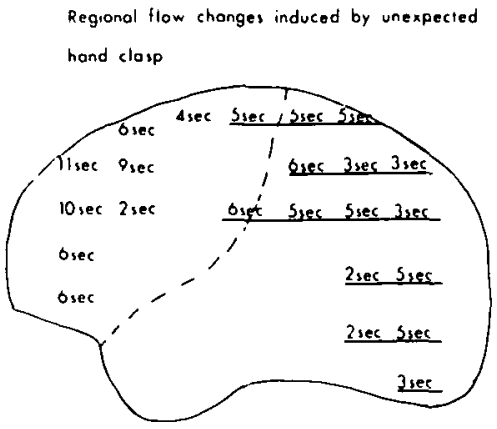

Duration of culmination flows.

- llows indicaling culmination of circulatory activation

Figure 7 - Duration of regional Croma-Flow measured at the end of the activation period and lasting until regional flow "deactivation"' ( = duration of culmination flow in seconds).

between the hand clasp and the start of regional flow changes is shown in Fig. 3. This shows latencies from zero to 6 seconds before flow increments or decrements start, in both frontal and parieto-occipital regions.

The time of continuing flow changes, i.e. the activation period, in the different cortical areas is shown in Fig. 4. The regional Croma-Flow values before the induced flow change and when a new steady state is reached after completion of flow increase or decrease (i.e. culmination flows) is represented by Fig.5. Based upon these two measurements the flow change per second per region, i.e. rate of activation, was calculated and the result is given in Fig. 6. The duration of the culmination flows was also determined, and shown in Fig. 7. Note from figures 9 and 10 that flow in some regions began to return to prestimulation levels while the stimulus was still maintained.

Using the average Croma-Flow as the ordinate and the time in seconds as the abscissa, plots were constructed by hand. Two periods are shown. The first represents the control condition before the hand clasp as shown by the interval from seconds 30-46 (Fig. 8). The upper part of the figure represents the regions in which flow increased during the hand clasp, the lower part represents the regions in which flow was lowered during this period. This figure is to be compared with a similar plot that covers seconds nr. 55-80 (Fig. 9). The hand clasp period of 16 seconds is marked by interrupted verticals. The difference of the flow pattern between the two periods is striking.

During rest, flow oscillated within narrow limits and the flow in the frontal regions was slightly higher than in the parieto-occipital areas. The constancy of the Croma-Flow values in this period suggests that the initial 1-2 minutes of the xenon washout curve is normally mono-exponential and is dominated by the tissue with the highest perfusion, the grey matter of the cerebral cortex. This pattern was completely changed following the hand clasp. In the frontal regions flow was lowered and two to three regions turned white (plotted as zero). Soon after completion of the hand clasp, and in some before completion, flow returned towards pre-stimulation levels. In the parieto-occipital regions flow increases of up to 400 percent occurred. Other cortical regions remained silent during the activation period as revealed in Fig. 10.

It is not within the scope of this communication to discuss the results in the terms of perception physiology or mind-brain relationship. This study was chosen because the patient was without gross neurological deficits and because the results were not influenced by previous information or instruction. 


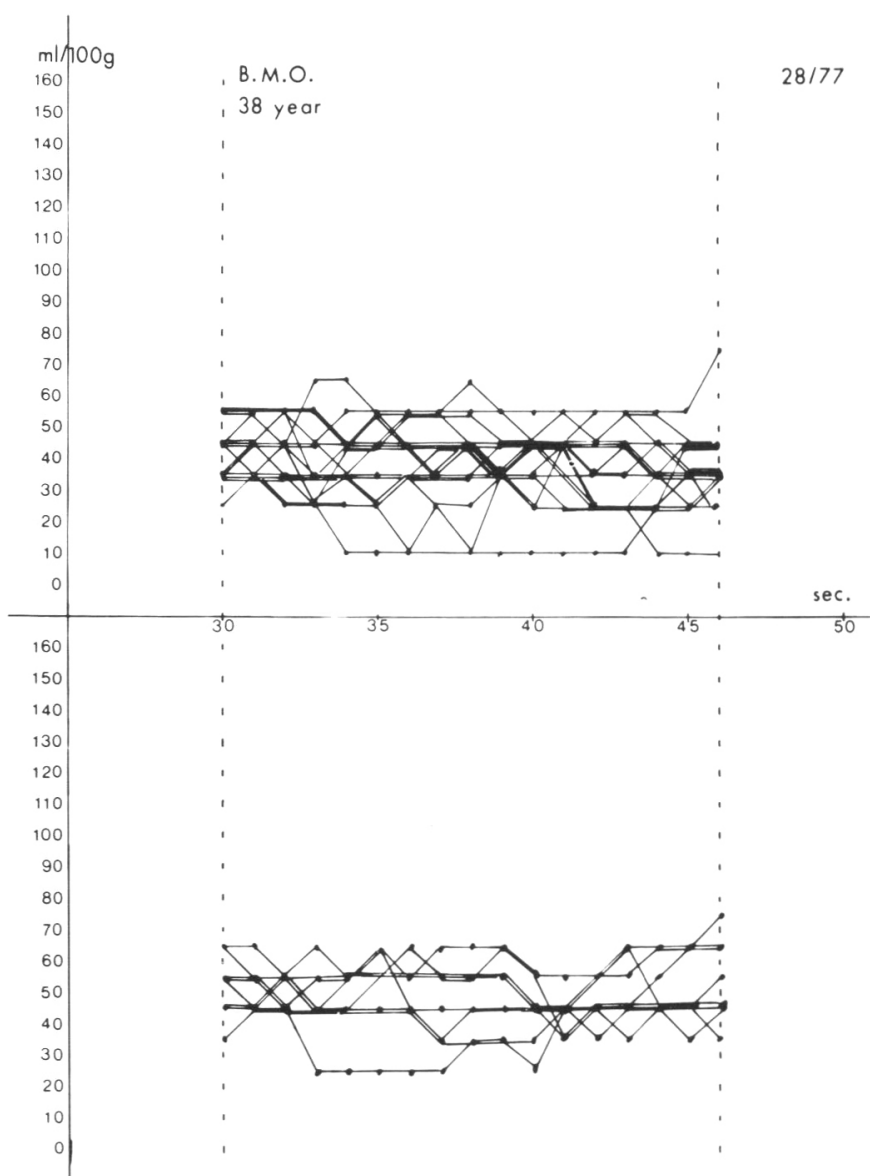

Figure 8 - The ordinate denotes assumed average of CromaFlow, the abscissa indicates the time in seconds at which the flow was calculated. The chosen period is from seconds 30-46, a silent period with regard to psycho-physical stimulation. The upper part displays parieto-occipital regions, the lower part frontal regions.

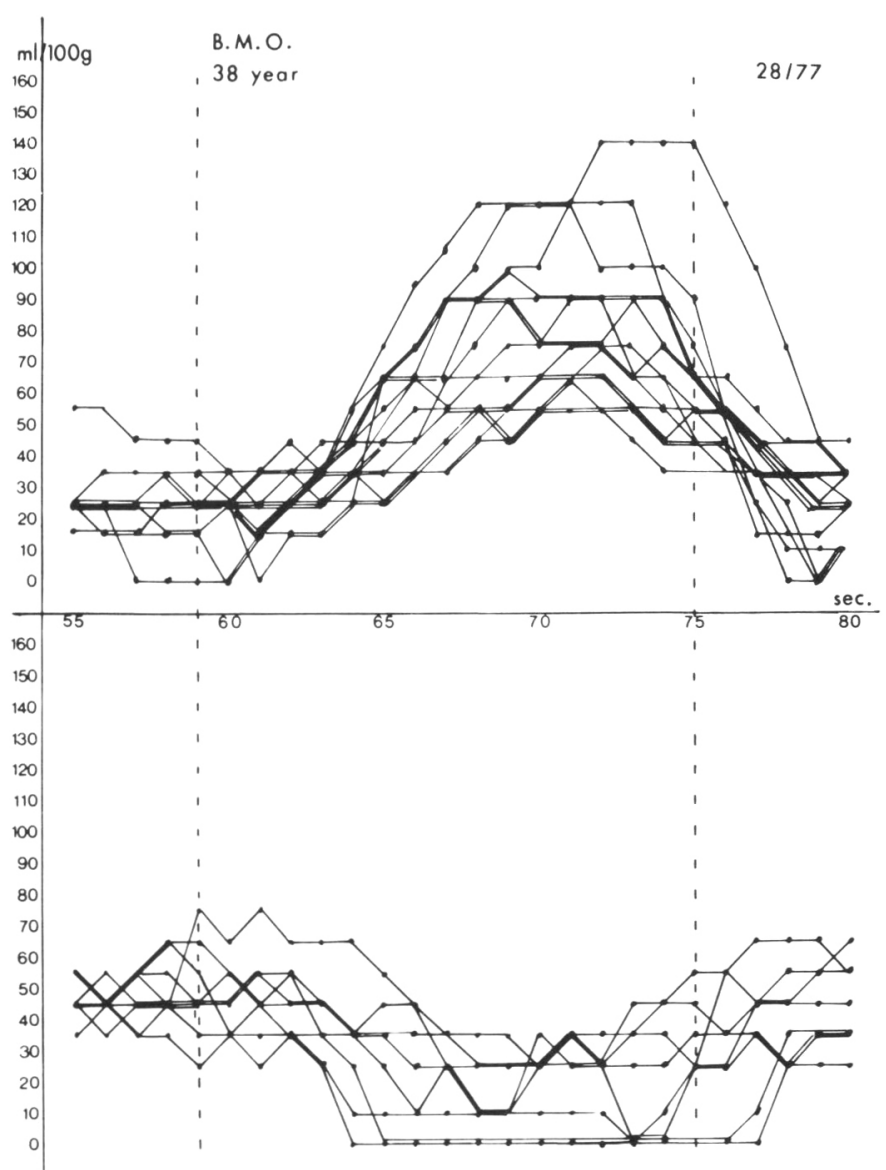

Figure 9 - This figure is constructed as figure 8 , but shows between the interrupted verticals the hand clasp period (seconds 59-75). Regions are distributed as in Figure 8. The latency, activation period, duration of culmination flow are all determined from the $x / y$ plot of each detector, representing a region.
The explanation of the CromaFlow increase in the parietooccipital region may not be based only on gnostic analysis of skincontact. It is suggested that the patient tried to look through the covering cloth for visual analysis at the moment of hand clasp, and this response was "automatic" (i.e. extra lemniscal reticular formation conveyed) and did not activate the frontal oculomotor areas. It is also of interest that focal activation and hyperemia of one area of cortex was associated with transient reductions of flow in other areas, i.e. an acute redistribution.

Cerebral pathology exerts a pronounced influence on regional cerebral blood flow, in both the resting state and under physical activation (Ingvar and Risberg, 1967; In- gvar and Ciria, 1975; Ingvar, 1976). This was also demonstrated at a second study, two weeks postoperative, in this patient. Her condition had deteriorated; she was aspontaneous, aphasic. Hyperventilation revealed a paradoxical response to $\mathrm{PaCO}_{2}$ changes in several regions of the middle cerebral artery territory. A sudden hand clasp was again applied and the regional flow responses were similar to the preoperative findings, but the time relation was prolonged and the flow changes less pronounced.

\section{B. Summary of Croma-Flow \\ Experience to Date}

We have used the described modification of the rCBF init. technique together with the conventional dis- play in more than 40 clinical studies during the last six months. None of these were normal. All the patients were under investigation for neurosurgical intracranial disease and most were medicated with barbiturates.

Until now the Croma-MemoFlow system has offered useful information about the timing of regional cortical rCBF responses in a variety of conditions - such as arterio-venous shunts, secondary continuing myoclonus, sudden regional hyperemia in impending brain herniation, cortex infiltrating tumors and brain contusion. In such cases the time relation of the distorted washout curves called "shunt-peaks" and "tissue-peaks" have been measured (Olesen et al., 1971). 
B.M.O.

38 year

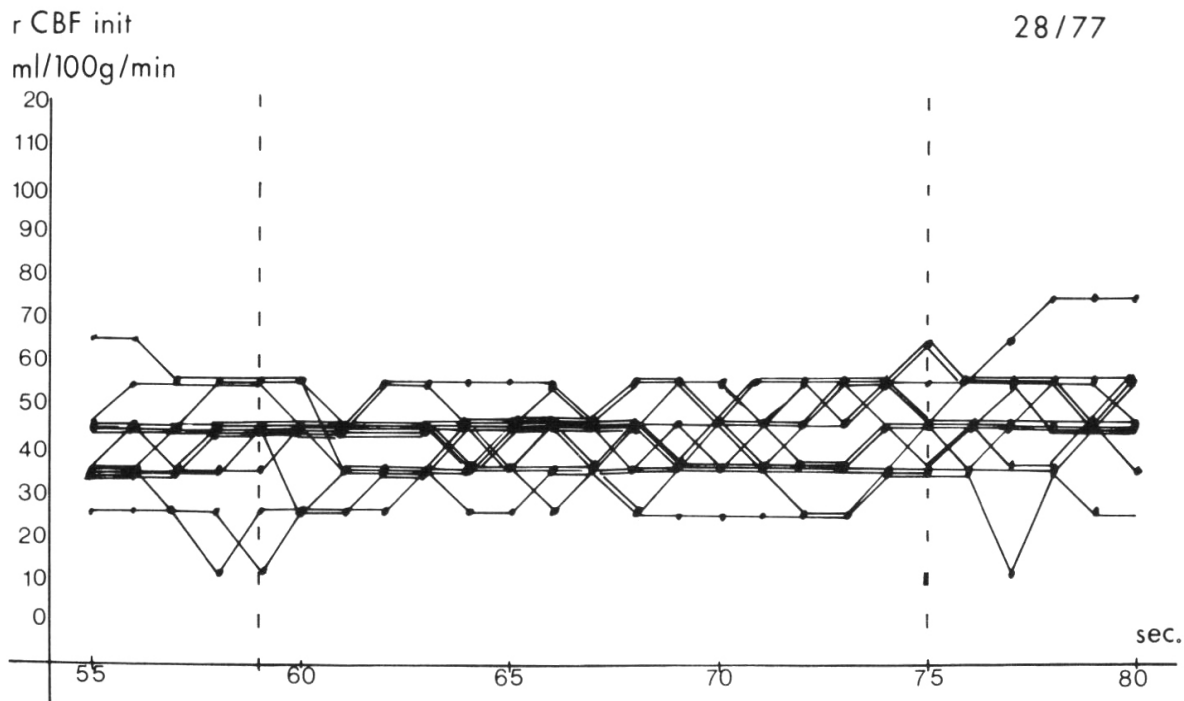

Figure 10 - This figure is constructed as the two previous and represents Croma-Flow during the hand clasp period from second 59-75 in the regions that did not take part in the redistribution of flow caused by the stimulus; in figure 3-7 they are located as the blank regions.

A consistent feature of the Croma display has been small flow fluctuations. These may represent inaccuracy of the flow calculations, random variation or noise, but they may also reflect aspects of biological regulation, as the "oscillations" vanish during flow changes (activation period) in most of the regions activated by brain stimulation, regardless of the direction of the flow change (see Figure 9). The start and stop effect of the psychophysical stimulus is also clearly revealed in this figure. In a silent region, a region not activated by the stimulus, the "oscillation" pattern continues although the fluctuations stop in the activated regions (see Fig. 10). In the patients with focal cortical pathology associated with regional hyperemia, flow fluctuations are also reduced or suspended. In comparable cases studied with the conventional $\mathrm{rCBF}$ init. method and biopsied, we found a rather good correlation between regional hyperemia and brain tissue lactate (Hjelm et al., 1975), suggesting that lactic acidosis of tissue perhaps disrupts a normal cyclical regulating mechanism.
A simple functional test, repetitive pressing of the handle of a dynamometer (Olesen, 1971), has been performed in 23 examinations in patients with different focal cerebral pathology. Activation was started 25-40 seconds "down the slope" and the circulatory reaction was therefore visualized on the TV screen during the test.

The variation of the latencies was surprising. The earliest focal flow increase occurred at 5 seconds, in many as late as 12 seconds and in a few nothing happened. Usually one region was activated at first, followed seconds later by neighboring regions. The response to the sudden hand clasp "test" was only as distinct as shown here in a few cases. Cerebral pathology is the important inhibitor of functional flow activation.

\section{APPLICATIONS AND LIMITATIONS}

The latencies measured in the different regions seem reasonable (Cooper et al., 1975; Severinhgaus, 1975). However, we do not know how exactly they reflect the time elapsed between stimulus and reg- ional flow response. This is because of the time constants of the measuring system, which makes a zero-time relation unreliable (see Fig. 3). Reservations are relevant also when considering the complete stimulus period of 16 seconds (the hand clasp) and the duration of the culmination flow (i.e. flows indicating culmination of circulatory activation) in the different regions (see Fig. 9). The duration as well as the "plateaus" of some of the flow responses may be explained by the greater flow intervals of the Croma-Flow, when the calculated value is over 90 $\mathrm{ml} / 100 \mathrm{~g} / \mathrm{min}$.

One advantage of this modification of the rCBF init. technique is the possibility of using the same clearance curve for assessment of both the resting condition and the test response. This exploitation is at variance with common practice (Larsen et al., 1976; Olesen, 1971; Roland and Larsen, 1976) and theoretical objections may be advanced (Zierler, 1965). It must, however, be noted that the condition for the flow calculations is the presence of a slope and provided the coupling between tissue metabolism and flow is perfect it is probably unimportant which part of the curve is used for the calculations. Slope determination based upon identifiable, short, sequential portions of the washout curve increases the sensitivity of the recording system to brief functional flow changes, which may remain undiscovered when the slope is calculated only once, i.e. after the standard measuring time of $60 \mathrm{sec}-$ onds.

It may be postulated, based upon measurements of time relations outlined briefly in the text, that the calculation of flow change/second/region may be regarded as an expression of the flow adjustment to meet the metabolic demands of the activated tissue. The patient study illustrates this prospect (see Fig. 6), but it must be emphasized that the present equipment displays flow intervals and the plots of the Croma-Flow are made on assumed average values of those intervals. However, the memory of the system also stores specific data 
which will be used in the future for an electronic display of the $x / y$ plot of flow versus time. Other limitations are related to the time constants and the statistics of flow calculations. For the regional resolution more detectors are desirable and the position of the detectors relative to the brain surface may also be improved.

\section{ACKNOWLEDGMENT}

The author acknowledges the interest and work by Birte Bak Frederiksen who made the drawings and Beth Tang who typed the manuscript, and Dr. Niels Lassen and Prof. D. H. Ingvar for inspiring discussions.

Financial support was donated from the Odense County Hospital and Odense University.

\section{REFERENCES}

ALBERT, M. L. and BEAR, D. (1974): Time to understand. Brain, 97, 373-384.

COOPER, R., PAPAKOSTOPOULOS and CROW, H. J. (1975): Rapid Changes of Cortical Oxygen Associated with Motor and Cognitive Function in Man. - p.: 14.8-14.9 in: Blood Flow and Metabolism in the Brain. Ed.: A. M. Harper, W. B. Jennett, J. D. Miller \& J. O. Rowan. Churchill Livingstone (ISBN 044301386 1).

DYKES, R. W., NELSON, G. P. TANJI, G. D. and DUDAR, J. D. (1977): Multiple loci of evoked potentials in somatosensory cortex. Brain Research, 124, 162-167.

EFRON, R. (1963): Temporal perception, aphasia and déjá-vu. Brain, 86, 403-424.
GLICKSTEIN, M. (1972): Brain Mechanisms in Reaction Time Brain Research, 40, 33-37.

HJELM, M., OVERGAARD, J., LASSEN, N. A. and TWEED, W. A. (1975): Brain Tissue Lactacidosis of Hyperemic Regions around Brain Tumors. in: Blood Flow and Metabolism in the Brain. - ed.: A. M. Harper, W. B. Jennett, J. D. Miller \& J. O. Rowan. p.: 13.41-13.42. Churchill Livingstone (ISBN 044301386 l).

INGVAR, D. H. and RISBERG, J. (1967): Increase of regional cerebral blood flow during mental effort in normals and in patients with focal brain disorders. Expt. Br. Res: 5, 72-78.

INGVAR, D. H. and GUSTAFSON, L. (1970): Regicnal Cerebral Blood Flow in Organic Dementia with early onset. Acta Neurol. Scand: Suppl. 43, vol. 46, 42-73

INGVAR, D. H. and FRANZEN, G. (1974): Abnormalities of Cerebral Blood Flow Distribution in Patients with Chronic Schizophrenia Acta phychiatr, scand., 50, 425-462.

INGVAR, D. H. and CIRIA, H. G. (1975): Assessment of severe damage to the brain by multiregional measurements of cerebral blood flow. p.: 97-120. in: Outcome of Severe Damage to the Central Nervous System; Ciba Foundation Symposium 34 (new series). Elsevier - Excerpta Medica - North Holland, Amsterdam. (ISBN 90 21940388 and 0444-15182-6)

INGVAR, D. H. (1976): Functional Landscapes of the dominant Hemisphere. Brain Research, 107, 181-197.

LARSEN, B., ENDO, H. and LASSEN, N. A. (1976): Patterns of Activation of the Human Cerebral Cortex as Evidenced by Changes in Regional Cerebral Blood Flow. Acta Physiol. Scand. 96/3 (D 13).

LASSEN, N. A. and INGVAR, D. H. (1972): Radioisotopic Assessment of Regional Cerebral Blood Flow. Progr. nucl. Med., vol. 1, 376-409.
MOSFELDT LAURSEN, A. (1967): Higher Functions of the Central Nervous System. An. Review of Physiology, vol. 29, 543-572.

OLESEN, J. (1971): Contralateral Focal Increase of Cerebral Blood Flow in Man During Arm Work. Brain, 94, 635-646.

OLESEN, J., PAULSON, O. B. and LASSEN, N. A. (1971): Regional Cerebral Blood Flow in Man Determined by the Initial Slope of the Clearance of Intraarterially Injected 133-Xe. Stroke, vol. 2, 519-540.

RAICHLE, M. E., GRUBB, R. L., GADO, M. H., EICHLING, J. O. and TERPOGOSSIAN, M. M. (1976): Correlation Between Regional Cerebral Blood Flow and Oxidative Metabolism, - In Vivo Studies in Man. Arch, Neurol., vol. 33. 523-526.

RISBERG, J. and INGVAR, D. H. (1973): Patterns of activation in gray matter of the dominant hemisphere during memorizing and reasoning. Brain, 96, 737-756.

ROLAND, P. E. and LARSEN, B. (1976): Focal Increase of Cerebral Blood Flow During Stereognostic Testing in Man. Arch. Neurol. vol. 33, 551-558.

SEVERINGHAUS, J. W. (Ed) (1975): Coupling Mechanisms, Flow to Function and Metabolism in Brain, a General Discussion. p. 503-517 in Alfred Benzon Symposium VIII, Brain Work, The Coupling of Function, Metabolism and Blood Flow in the Brain. - Ed. by Ingvar, D. H. \& Lassen, N. A., Munksgazrd, Copenhagen. (ISBN 0 12 - $371050-2)$.

SVEINSDOTTIR, E., LARSEN, B., ROMMER P. and LASSEN, N. A. (1977): A Multidetector Scintillation Camera with 254 Channels. J. Nucl. Med., 18, nr. 2, 168-174.

ZIERLER, K. L. (1965): Equations for Measuring Blood Flow by External Monitoring of Radioisotopes. Circ. Res. vol. XVI, 309-321. 